\title{
Design Rationale and Development Approach for Pegfilgrastim as a Long-Acting Granulocyte Colony-Stimulating Factor
}

\author{
Tara Arvedson $^{1} \cdot$ James O'Kelly $^{2} \cdot$ Bing-Bing Yang ${ }^{1}$
}

Published online: 22 May 2015

(c) The Author(s) 2015. This article is published with open access at Springerlink.com

\begin{abstract}
Filgrastim, a recombinant methionyl human granulocyte colony-stimulating factor (G-CSF) ( $\mathrm{r}-$ metHuG-CSF), is efficacious in stimulating neutrophil production and maturation to prevent febrile neutropenia (FN) in response to chemotherapy. Because of its relatively short circulating half-life, daily filgrastim injections are required to stimulate neutrophil recovery. In an effort to develop a long-acting form of filgrastim that was as safe and efficacious as filgrastim but had a longer in vivo residence time, a number of strategies were considered. Ultimately, fusion of filgrastim to polyethylene glycol (PEG) was selected. Following extensive analysis of conjugation chemistries as well as in vitro and in vivo characterization of a panel of PEGylated proteins, a construct containing a $20 \mathrm{kDa}$ PEG moiety covalently conjugated to the N-terminus of filgrastim was chosen for advancement as pegfilgrastim. Pegfilgrastim is primarily cleared by neutrophils and neutrophil precursors (rather than the kidneys), meaning that clearance from the circulation is selfregulating and pegfilgrastim is eliminated only after neutrophils start to recover. Importantly, addition of PEG did not alter the mechanism of action and safety profile compared to filgrastim. Clinical evaluation revealed that a single $6 \mathrm{mg}$ dose effectively reduces the duration of neutropenia and risk of FN in patients receiving chemotherapy. This work demonstrates the benefit of using PEGylation to generate pegfilgrastim, which allows for once-per-chemotherapy cycle administration while maintaining similar
\end{abstract}

Tara Arvedson

tara.arvedson@amgen.com

1 Amgen Inc., 14-1-B, One Amgen Center Drive, Thousand Oaks, CA 91320-1799, USA

2 Amgen Ltd, Uxbridge, UK safety and efficacy profiles as those for multiple daily administration of filgrastim. Approaches that may provide advances for therapeutic agonists of G-CSF receptor are also discussed.

\section{Key Points}

Evaluation of multiple PEGylated forms of filgrastim identified pegfilgrastim, a $20 \mathrm{kDa}$ polyethylene glycol (PEG) fusion protein, as the construct with the optimal balance of in vitro activity and in vivo residence time.

Pegfilgrastim, having self-regulating clearance, remains in circulation during chemotherapy-induced neutropenia and is not eliminated until neutrophils start to recover.

Clinical efficacy of pegfilgrastim is achieved with a single $6 \mathrm{mg}$ dose once-per-chemotherapy cycle.

\section{Introduction}

Granulocyte colony-stimulating factor (G-CSF) is an endogenous hematopoietic growth factor that stimulates proliferation and differentiation of neutrophil precursors and increases survival and activity of mature neutrophils [1]. Neutrophils, the most abundant white blood cells in circulation, play a critical role in innate immunity and also influence the adaptive immune response. The protective role of neutrophils is demonstrated by the severe and sometimes fatal 
infections that are developed by patients with congenital or induced neutrophil deficiencies; in these patients the risk of infection is proportional to the extent of neutropenia [2].

Neutrophils are short-lived cells and remain in circulation for only hours to a few days [3, 4]. To maintain supply, approximately $10^{7}$ neutrophils are produced each second, requiring an estimated two-thirds of the bone marrow's hematopoietic space. This output requires the rapid proliferation of granulocyte precursors [5], making them highly susceptible to cell death in patients being treated with cytotoxic cancer chemotherapy. The reduction in neutrophil number during chemotherapy increases the risk of infection and hospitalization, as well as the risk of reducing the chemotherapy dose and/or delaying the chemotherapy treatment [6]. As a consequence, severe neutropenia can increase the risk of mortality both in the short-term (due to infections) and long-term (due to receiving insufficient intensity of chemotherapy) [7-9].

To address the risk of complications associated with neutropenia in patients receiving myelosuppressive chemotherapy, recombinant methionyl human G-CSF (rmetHuG-CSF; filgrastim) was approved by the US FDA in 1991. Filgrastim decreases the incidence of infection as manifested by febrile neutropenia (FN) in patients with non-myeloid malignancies receiving myelosuppressive chemotherapy. Filgrastim has a relatively short circulating half-life $(3.5 \mathrm{~h})$ [10], necessitating daily administration until neutrophil recovery. Furthermore, filgrastim requires bodyweight-based dosing (starting at $5 \mu \mathrm{g} / \mathrm{kg} /$ day) and frequent monitoring of neutrophil counts [11], which increase the challenge of compliance. To enhance the product characteristics, a variety of approaches to develop a long-acting version of filgrastim were considered and tested. By adopting a systematic approach and following a series of rigorous testing procedures, pegfilgrastim emerged as a G-CSF that can significantly reduce the risk of neutropenia and related complications with one administration per chemotherapy cycle [12-14].

Pegfilgrastim has been used in clinical practice since 2002, and its efficacy and safety have been demonstrated in a variety of tumor types and settings [15-18]. With the ongoing development of other long-acting G-CSF molecules and the expected arrival of pegfilgrastim biosimilars in the next few years, there is increased interest in understanding the basis of the structure-function relationship important for developing a long-acting G-CSF. Although the development program of pegfilgrastim has been described elsewhere [19], a detailed overview of the early non-clinical work and the scientific approach taken to select PEGylation as the G-CSF conjugate is lacking. The objective of this review is to describe the rationale, clinical implications, and scientific data of the PEGylation approach used in the development of pegfilgrastim.

\section{Filgrastim}

Clinical experience with filgrastim extends for more than 20 years, and has been reviewed extensively $[1,20]$. The initial approval was based on two randomized clinical studies in patients with lung cancer that demonstrated that filgrastim treatment significantly reduced the duration of severe neutropenia, the number of days of hospitalization, the incidence of antibacterial treatment, and the number of chemotherapy dose reductions [15, 21, 22]. Filgrastim has additionally been approved for use in patients with acute myeloid leukemia, severe congenital neutropenia, AIDSassociated neutropenia, and to speed neutrophil recovery in cancer patients receiving bone marrow transplant. It is also approved for patients undergoing peripheral blood progenitor cell collection.

In patients undergoing chemotherapy, it is recommended that filgrastim dosing start $24 \mathrm{~h}$ after the completion of chemotherapy and be continued daily until the absolute neutrophil count (ANC) is $\geq 10 \times 10^{9}$ cells/ $\mathrm{L}$, which, in some cases, may require one injection each day for 10-14 days. To eliminate the need for patients to either return daily to their treatment center or to self-inject, a long-acting form of filgrastim was desired. Strategies to extend the duration of action include prolonged delivery (e.g., slow absorption from a drug reservoir) or half-life extension (i.e., to maintain concentrations in the blood). Filgrastim itself is relatively unstable for extended periods of time at physiologic temperature and $\mathrm{pH}$ [23], making a prolonged delivery option less desirable. Therefore, it was preferable to pursue a form of filgrastim with a longer elimination half-life; achievable by modulating the rate of filgrastim clearance. The desired properties of a long-acting filgrastim are summarized in Table 1.

Filgrastim, being a protein, can be cleared by proteolysis; however, its primary clearance pathways are renal- and neutrophil-mediated; for the latter, after binding of filgrastim to the G-CSF receptor (G-CSF-R) on neutrophils and neutrophil precursors, the filgrastim-G-CSF$\mathrm{R}$ complex is internalized and degraded. In neutropenic individuals, neutrophil-mediated clearance is significantly reduced, and renal clearance becomes dominant. Therefore, if renal clearance could be eliminated or significantly reduced while neutrophil-mediated clearance was retained, the drug would remain in circulation during neutropenia and be cleared only when the neutrophils start to recover, effectively resulting in a selfregulating therapeutic. Strategies to reduce renal clearance include making the protein larger, more elongated, or more negatively charged as these attributes make the protein less likely to be filtered by the renal glomeruli $[24,25]$. 
Table 1 Considerations for developing a long-acting form of filgrastim

\begin{tabular}{|c|c|c|}
\hline Parameter & Filgrastim properties & Requirements of a long-acting filgrastim \\
\hline $\begin{array}{l}\text { Drug clearance } \\
\text { mechanisms }\end{array}$ & $\begin{array}{l}\text { Subject to renal clearance } \\
\text { Subject to neutrophil- } \\
\text { mediated clearance }\end{array}$ & $\begin{array}{l}\text { Elimination or significant reduction of renal clearance while retaining neutrophil-mediated } \\
\text { clearance, allowing the drug to remain in circulation during neutropenia and be cleared } \\
\text { rapidly only when the neutrophils start to recover. This molecule should be able to provide } \\
\text { an effective serum concentration of G-CSF for a complete chemotherapy cycle }\end{array}$ \\
\hline Efficacy & $\begin{array}{l}\text { Reduces duration of severe } \\
\text { neutropenia } \\
\text { Reduces incidence of FN } \\
\text { Reduces infections } \\
\text { Reduces hospitalization }\end{array}$ & $\begin{array}{l}\text { Efficacy should be equivalent to or better than that for filgrastim across a broad range of tumor } \\
\text { types }\end{array}$ \\
\hline Safety & Acceptable safety profile & $\begin{array}{l}\text { No additional or more severe on-target adverse events (e.g., bone pain) } \\
\text { No increase in immunogenicity }\end{array}$ \\
\hline
\end{tabular}

$F N$ febrile neutropenia, $G$-CSF granulocyte colony-stimulating factor

Table 2 Possible strategies considered for increasing the in vivo residence time of filgrastim

\begin{tabular}{|c|c|c|}
\hline Possible strategy & $\begin{array}{l}\text { Examples of other modified proteins } \\
\text { available around the time of pegfilgrastim } \\
\text { development }\end{array}$ & Factors considered for developing a long-acting filgrastim \\
\hline $\begin{array}{l}\text { Glycoengineering } \\
\text { Introduction of novel } \\
\text { glycosylation sites to the } \\
\text { recombinant protein }\end{array}$ & $\begin{array}{l}\text { Aranesp } \\
\text { Recombinant erythropoietin with higher } \\
\text { amounts of sialic acid-containing } \\
\text { carbohydrate } \\
\text { Approved in } 2001 \text { for treatment of anemia }\end{array}$ & $\begin{array}{l}\text { Successfully used to increase the half-life of erythropoietin } \\
\text { Would require re-development of the expression and } \\
\text { purification processes used for filgrastim, which may affect: } \\
\text { Inability to retain the established safety profile of filgrastim } \\
\text { Longer development time } \\
\text { Increased costs }\end{array}$ \\
\hline $\begin{array}{l}\text { Fusion to other proteins } \\
\text { Attachment of G-CSF to an } \\
\text { antibody Fc domain or } \\
\text { albumin }\end{array}$ & $\begin{array}{l}\text { Enbrel } \\
\text { Recombinant TNF receptor fused to the Fc } \\
\text { region of an IgG1 antibody } \\
\text { Approved in } 1998 \text { to treat various } \\
\text { autoimmune disorders }\end{array}$ & $\begin{array}{l}\text { Addition of the protein partner may necessitate a change in the } \\
\text { protein expression or purification process } \\
\text { Both the antibody Fc and albumin interact with other } \\
\text { endogenous proteins and this may affect G-CSF localization } \\
\text { and/or activity }\end{array}$ \\
\hline $\begin{array}{l}\text { PEGylation } \\
\text { Attachment of PEG to the } \\
\text { purified protein }\end{array}$ & $\begin{array}{l}\text { Adagen }^{\circledR} \\
\text { Adenosine deaminase fused to multiple } \\
\text { PEG molecules } \\
\text { Approved in } 1990 \text { for enzyme replacement } \\
\text { therapy } \\
\text { Oncaspar }^{\circledR} \\
\text { L-Asparaginase fused to multiple PEG } \\
\text { molecules } \\
\text { Approved in } 1994 \text { as chemotherapy for } \\
\text { leukemia }\end{array}$ & $\begin{array}{l}\text { Demonstrated to be clinically safe and effective for increasing } \\
\text { the half-life of other molecules } \\
\text { Would enable use of filgrastim as the starting material, } \\
\text { thereby keeping the same protein expression and purification } \\
\text { processes } \\
\text { Flexibility in properties of the new molecule due to the range } \\
\text { of PEG sizes and conformations possible } \\
\text { PEG polymers are relatively chemically inert } \\
\text { PEG may reduce immunogenicity, proteolysis, and protein } \\
\text { aggregation }\end{array}$ \\
\hline
\end{tabular}

$G$-CSF granulocyte colony-stimulating factor, PEG polyethylene glycol, $T N F$ tumor necrosis factor

\section{PEGylation of Filgrastim}

\subsection{Selection of PEGylation to Improve In Vivo Residence Time}

Options for increasing protein size include introducing novel glycosylation sites (glycoengineering) or fusing the protein to another protein, such as an antibody or serum albumin, or fusing the protein to a polymer such as polyethylene glycol (PEG). Many of these options were considered and the factors influencing the selection of PEGylation are summarized in Table 2. In particular, there was a desire to maintain the filgrastim core protein and to preserve the means of filgrastim production such that the extensive safety profile could be preserved in a long-acting molecule. 


\subsection{Physicochemical Properties of Polyethylene Glycol}

The PEGylation process involves the covalent attachment of PEG polymers to mature, purified protein. By starting with purified material there would be no need to change the core protein or the protein expression system to accommodate PEGylation. PEG molecules comprise repeating ethylene oxide units. The carbon-carbon and carbon-oxygen bonds are mobile, and there are no additional large or bulky groups on the polymer chain; as a result, the PEG molecules are highly flexible and tend to occupy a large space. Furthermore, because the oxygen interacts strongly with water, each ethylene oxide unit can coordinate 3-7 water molecules [26], creating a dynamic, hydrated polymer that is predicted to form a thick, flexible layer across the surface of the protein. With the addition of this layer, the PEGylated protein occupies a much larger volume than would be predicted based on the combined molecular weight of the protein and polymer alone. This effect becomes more magnified as the size of the PEG molecule increases, such that a $17 \mathrm{kDa}$ PEG molecule has a similar size as a $66 \mathrm{kDa}$ protein and a $50 \mathrm{kDa}$ PEG molecule has a similar size as a $476 \mathrm{kDa}$ protein [27]. This increase in the size of the PEG-protein conjugate increases the in vivo residence time as has been demonstrated for interferon IFN- $\alpha-2 b$ conjugated to a panel of PEG molecules with increasing molecular weight [28]. With the addition of PEG moieties of 10, 20, 30 and $45 \mathrm{kDa}$, the hydrodynamic radius (cumulative radius of the protein and PEG polymer) increased from $\sim 2 \mathrm{~nm}$ for unconjugated IFN- $\alpha-2 b$ to $5.7,7.4,9.1$, and $9.6 \mathrm{~nm}$ for the 10, 20, 30, and $45 \mathrm{kDa}-\mathrm{PEG}$ conjugates. The associated serum half-lives increased from $1.7 \mathrm{~h}$ for unconjugated IFN- $\alpha-2 b$ to $7.3,10.5,19.9$, and $23.9 \mathrm{~h}$ for the respective PEG conjugates. Similarly, the half-life of PEGylated human growth hormone increased from 1.4 to 6,15 , and $24 \mathrm{~h}$ upon conjugation to 2, 5, or $7.5 \mathrm{kDa}$ PEG constructs, respectively [29].

PEG molecules are available in different molecular weight ranges (e.g., 1-100 kDa) and in both linear and branched conformations, thereby enabling generation of a protein conjugate with specific properties. PEG polymers are relatively chemically inert, and have been shown to be safe when used as fusion partners in injectable protein therapeutics [30], in food and healthcare products (toothpaste can be up to $10 \%$ PEG [31]), and as excipients in various drug formulations [32]. Additional benefits of PEGylation include reports that it reduces immunogenicity [33], proteolysis [34], and protein aggregation [35]. Because of these advantageous properties, PEGylation was chosen as the means of increasing the in vivo residence time of filgrastim.

\subsection{Strategies for PEGylation of Filgrastim}

The first FDA-approved PEGylated proteins, Adagen ${ }^{\circledR}$ and Oncaspar $^{\circledR}$, were heterogeneous multi-PEG mixtures that differed in the number of attached chains and the site of attachment [36]. From our work on a long-acting filgrastim therapeutic, we came to the realization that having a conjugate with a single site of attachment would be preferred as it would be easier to demonstrate consistency and provide proof of quality; however, the techniques and reagents required for such a construct were still in development. One strategy to achieve site-selective addition of a PEG molecule available at the time was to target the free thiol from an unpaired cysteine. G-CSF contains five cysteines; however, four of these are involved in disulfide bonds and would not be available for PEG conjugation. The remaining cysteine (Cys 17) is not disulfide-linked but efforts to attach a PEG molecule to this site resulted in decreased activity. Structural analysis reveals that this cysteine is located near the interior of the protein [37] and attachment of the PEG molecule was likely disrupting the protein fold.

PEGylation of free amino groups is another strategy that was evaluated. Free amino groups in proteins are present in two instances: (1) the $\varepsilon$-amino group from the side chain of a lysine residue; or (2) the $\alpha$-amino group from the $\mathrm{N}$-terminus of the protein. While there is typically only one $\mathrm{N}$-terminus per protein chain (provided the protein chain is not cleaved to form multiple chains), lysines are frequently found on the surface of proteins. This abundance of accessible amino groups can lead to multiple PEG additions. For example, both Oncaspar ${ }^{\circledR}$ and Adagen ${ }^{\circledR}$ are PEGylated at multiple sites: Oncaspar ${ }^{\circledR}$ is reported to be PEGylated on 22 of its 33 free amino groups [38], and Adagen ${ }^{\circledR}$ is reported to be PEGylated on at least half of its 27 free amino groups [39], although exact figures have not been released by the Adagen ${ }^{\circledR}$ manufacturer.

G-CSF contains five free amino groups including the $\mathrm{N}$-terminus and four lysines at positions 16, 23, 34, and 40. Non-specific PEGylation of free amino groups in G-CSF was an approach pursued by other research groups around the same time as Amgen's initial work to develop a longacting filgrastim (Ro 25-8315 and PEG-rHuG-CSF; Table 3); however, none of these other early molecules has gained regulatory approval. In one example, PEG was added to filgrastim both at the four surface-exposed lysine residues and the $\mathrm{N}$-terminal methionine residue [40]. Analysis of this material revealed multiple species of modified proteins with different molecular weights. Another group used a mutated version of G-CSF (nartograstim), in which several amino acids from the recombinant G-CSF have been replaced [41]. PEGylation of this construct also resulted in multiple species of modified G-CSF with different molecular weights. 


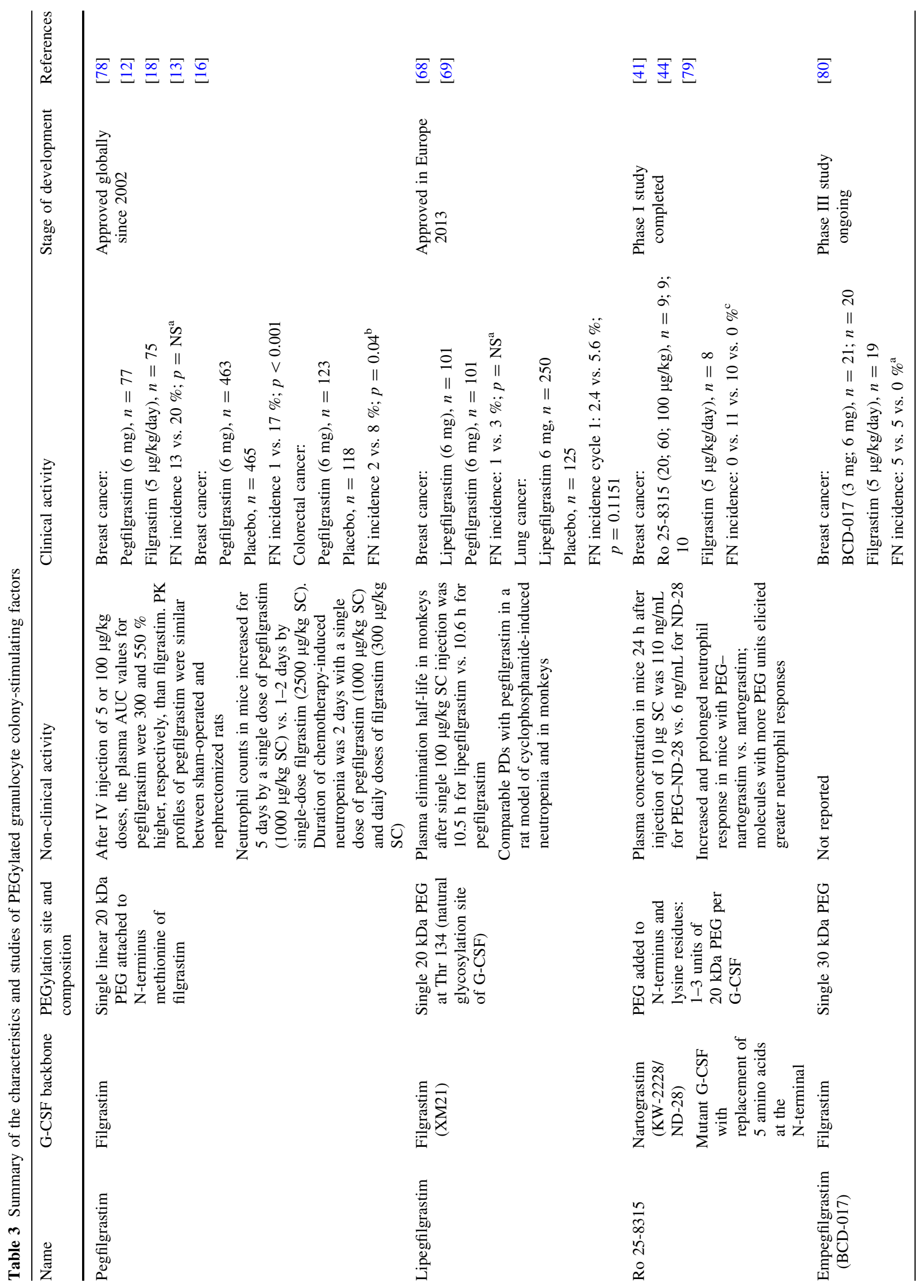




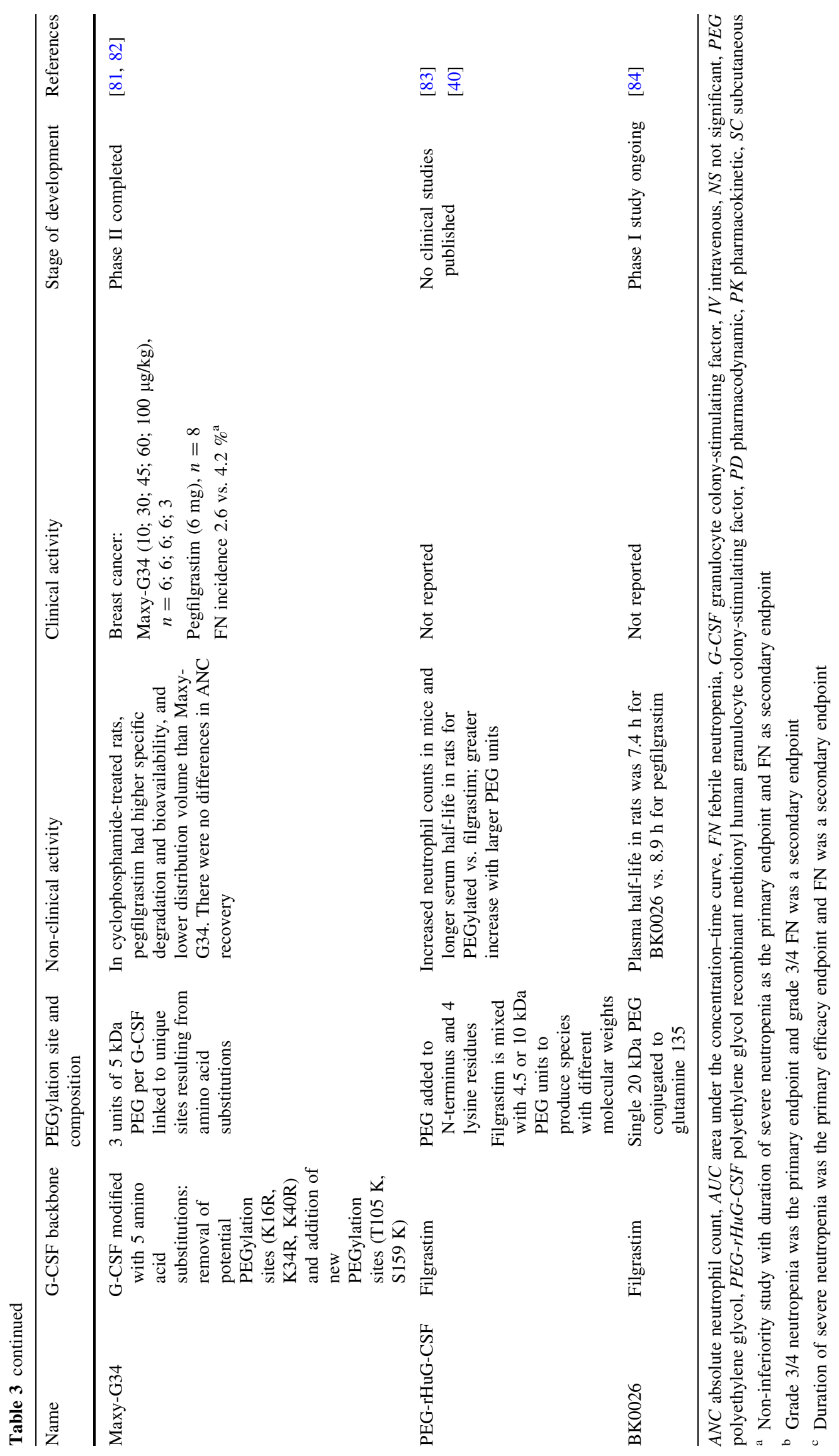




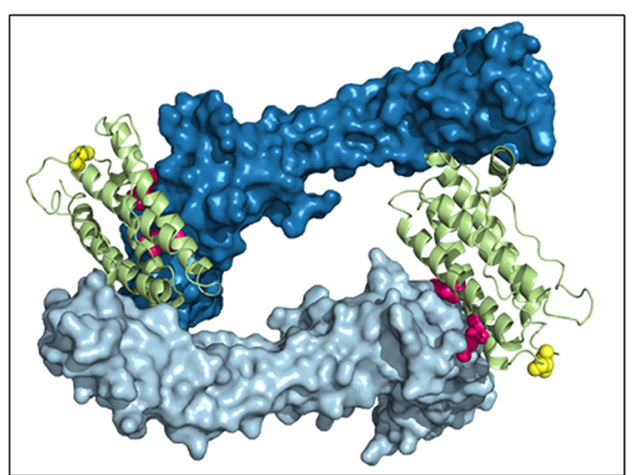

Fig. 1 The N-terminus of granulocyte colony-stimulating factor (GCSF) is distal from the receptor binding site while lysine residues 16 and 23 are located in the receptor binding site. Left panel the G-CSF:G-CSF receptor (G-CSF-R) signaling complex [42] comprises two G-CSF (green) and two G-CSF-R molecules (light and dark

While our initial efforts also involved non-specific PEGylation of free amino groups, our results suggested that PEGylation of the lysine residues interfered with receptor binding. Structural studies of the G-CSF/G-CSF-R complex subsequently showed that two of these lysine residues are located within the receptor-binding interface (Fig. 1) [41]. In comparison, PEGylation of the N-terminus did not significantly interfere with receptor binding; thus, for the long-acting filgrastim, we pursued a means of selectively PEGylating the $\alpha$-amino group from the $\mathrm{N}$-terminus. Although the G-CSF/G-CSF-R (domains 1-3) structure was not available when this choice was made, the cocrystal structure has confirmed that the $\mathrm{N}$-terminus is not involved in the G-CSF/G-CSF-R interaction and is pointing away from the ligand/receptor interface [42].

To achieve selective addition of the PEG moiety to the $\mathrm{N}$-terminal $\alpha$-amino group and limit reaction with the lysine $\varepsilon$-amino groups, it was necessary to identify conditions where the $\alpha$-amino group (acid dissociation constant $[\mathrm{pKa}]=7.6-8.0$ [43]) of the $\mathrm{N}$-terminus was more reactive than the lysine $\varepsilon$-amino groups $(\mathrm{pKa}=10.0-10.2[43]$ ). This was achieved by lowering the $\mathrm{pH}$ of the reaction and incorporating an optimized reactive PEG construct. In the end, the process that was selected involved reductive alkylation of G-CSF with a PEG aldehyde derivative at pH 5.

\subsection{Screening and Selection of an Appropriate PEGylated Filgrastim}

To select a long-acting filgrastim candidate for therapeutic use, a large panel of PEG-G-CSF conjugates was generated and characterized. The PEG moieties that were evaluated spanned a range of available molecular weight polymers $(12-30 \mathrm{kDa})$ and comprised both linear and branched conformations. The extent of reaction was

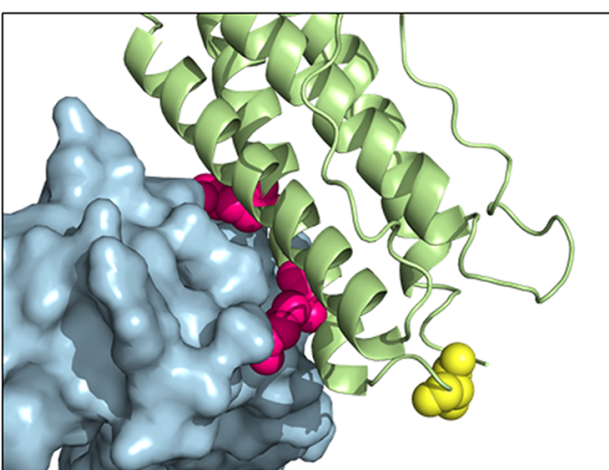

blue). The atoms of the G-CSF N-terminus are marked with yellow balls. The atoms of lysines 16 and 23 are marked with pink balls. Right panel a close-up of the interface providing more detail regarding the location of lysines 16 and 23

monitored by high-performance liquid chromatography (HPLC) to ensure a high percentage of conjugation, followed by purification, and verification of the site of addition using endoproteinase peptide mapping and additional physiochemical characterization [ultracentrifugation, MALDI (matrix-assisted laser desorption/ionization) TOF (time-of-flight) mass spectrometry, and size exclusion HPLC with associated in-line light scattering]. This characterization ensured appropriate composition, stoichiometry, and structure of the conjugates. More than 25 constructs were evaluated for in vitro and in vivo activity; the in vitro activity score was derived from results in a cellbased proliferation assay using cells stably expressing the G-CSF-R and the in vivo activity score was based on the area under the concentration-time curve (AUC) of the ANC in healthy animals.

As shown in Fig. 2, there was a positive relationship between the molecular weight of the added PEG and the in vivo activity of the modified filgrastim. Similar results were obtained by other researchers with PEGylated filgrastim or nartograstim [41, 44], whereby white blood cell counts in mice were found to increase as the size or number of PEG units was increased [55]. In those studies, like our own, it was also observed that molecules with increased in vivo activity demonstrated decreased in vitro activity. In general, these characteristics became more magnified as the molecular weight of the PEG molecule increased. The decreased in vitro activity is likely a consequence of the PEG molecule interfering directly and/or indirectly with G-CSF binding to its receptor. This is likely a consequence of the PEG molecule's bulk and mobility which could cause periodic occlusion of the binding interface, slowing the on-rate of binding. A similar relationship between enhanced in vivo activity and decreased in vitro activity has been observed for PEG conjugates of human growth hormone [29] and asiolofetuin [45]. The result of our studies 


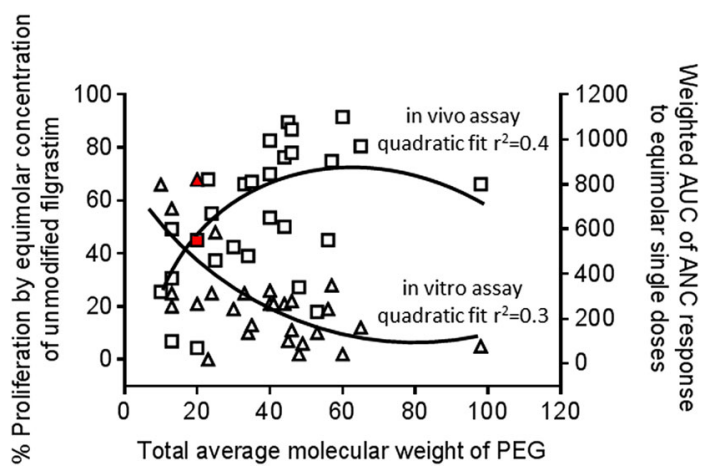

Fig. 2 PEGylation-mediated increases in vivo activity were associated with decreases in vitro activity. The in vitro and in vivo activity of various polyethylene glycol (PEG)-recombinant methionyl human granulocyte colony-stimulating factor (G-CSF) (r-metHuG-CSF) constructs were assessed and plotted according to the amount of PEG added per molecule. For candidates that were pegylated at multiple sites, the amount of PEG reflects the total molecular weight of the PEG additions. Triangles indicate the proliferation induced in cell line 32D clone 3 stably expressing human G-CSF receptor. Squares indicate the weighted area under the concentration-time curve (AUC) obtained from the daily average absolute neutrophil count (ANC) from mice ( $n=5 /$ timepoint) weighted by multiplying by the number of days after injection, then summed. The red triangle and the red square mark the in vitro and in vivo activity of the pegfilgrastim construct selected for further development. Reproduced from Molineux [13] with permission of Springer Science + Business Media (ㄷ Birkauser Verlag/Switzerland)

was the selection of an r-metHuG-CSF-PEG conjugate containing a single linear $20 \mathrm{kDa}$ PEG attached to the $\mathrm{N}$-terminal methionine. This construct would become pegfilgrastim.

\section{Pegfilgrastim}

\subsection{Non-Clinical Evaluation of Pegfilgrastim Activity}

The in vivo activity of pegfilgrastim compared to filgrastim was evaluated in both normal and neutropenic mice by subcutaneous (SC) injection. ANC is commonly used as a pharmacodynamic marker because it is straightforward to measure and represents the target cell for eliciting clinical benefit in neutropenic patients. In normal mice a single dose of pegfilgrastim (1000 $\mu \mathrm{g} / \mathrm{kg} \mathrm{SC})$ increased the ANC for 5 days, whereas a single injection of filgrastim at a higher dose $(2500 \mu \mathrm{g} / \mathrm{kg} \mathrm{SC})$ increased the ANC for only 1-2 days (Fig. 3a). In a model of chemotherapy-induced neutropenia, control mice that received neither filgrastim nor pegfilgrastim experienced 7 days of neutropenia, whereas mice treated with either daily filgrastim $(300 \mu \mathrm{g} /$ $\mathrm{kg}$ SC, days 2-11) or a single dose of pegfilgrastim (a)



(b)

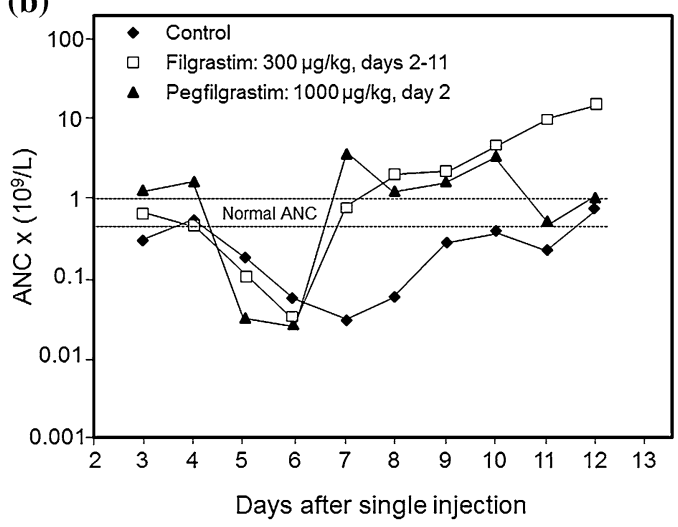

Fig. 3 Pegfilgrastim has enhanced in vivo activity relative to filgrastim. a Splenectomized mice were treated with a single injection of carrier, filgrastim, or pegfilgrastim and the absolute neutrophil count (ANC) was measured daily. Each timepoint represents 5-10 mice. b A single injection of pegfilgrastim is as effective as daily injections of filgrastim at restoring a normal neutrophil count in mice with chemotherapy-induced neutropenia. Neutropenia was induced in mice using a single intravenous injection of 5-fluorouracil $150 \mathrm{mg} / \mathrm{kg}$ on day 0 . Mice were then randomized $(n=40$ mice/group) and treated with carrier, daily injections of filgrastim $300 \mu \mathrm{g} / \mathrm{kg}$ (days $2-11$ ), or a single injection of pegfilgrastim $1000 \mu \mathrm{g} / \mathrm{kg}$ on day 2 . Daily ANC values were derived using four mice/group. Reproduced from Molineux et al. [78] with permission from Elsevier (ㄷ 1999 International Society for Experimental Hematology)

(1000 $\mu \mathrm{g} / \mathrm{kg} \mathrm{SC}$ ) experienced only 2 days of neutropenia (Fig. 3b). These data demonstrated that a single injection of pegfilgrastim was as effective in stimulating neutrophil recovery as multiple daily injections of filgrastim.

Pegfilgrastim exhibited an acceptable non-clinical safety profile in short- and long-term studies across a range of species-including rats, rabbits, and Cynomolgus monkeys - using delivery by SC and intravenous routes. By retaining filgrastim as the core of the molecule, a predictable safety profile was possible because pegfilgrastim, like endogenous G-CSF, is specific for only one receptor. Furthermore, this safety profile shows that addition of the PEG molecule to filgrastim did not cause significant qualitative changes in the filgrastim pharmacology/safety profile and no off-target toxicities were identified. 


\subsection{Pharmacokinetics of Pegfilgrastim}

The pharmacokinetics of pegfilgrastim have been described in recent review articles [46, 47] and are summarized briefly here. The prolonged in vivo activity of pegfilgrastim compared with filgrastim can be explained by the nearly negligible role played by the kidneys in pegfilgrastim clearance. The reduction in renal elimination was demonstrated in bilaterally nephrectomized rats. In this model, clearance of filgrastim $100 \mu \mathrm{g} / \mathrm{kg}$ was reduced by $75 \%$ in nephrectomized compared with sham-operated rats. By comparison, clearance of pegfilgrastim $100 \mu \mathrm{g} / \mathrm{kg}$ was similar in both the nephrectomized and sham-operated rats (Fig. 4a) [48]. This clearly demonstrated that renal clearance had been greatly reduced. To evaluate the role of the kidney in pegfilgrastim clearance in humans, the pharmacokinetic profile for pegfilgrastim was evaluated in subjects with varying degrees of renal function ranging from normal to mildly, moderately, and severely impaired as well as subjects with end-stage renal disease [49]. Across all groups, the pharmacokinetic profile of pegfilgrastim was
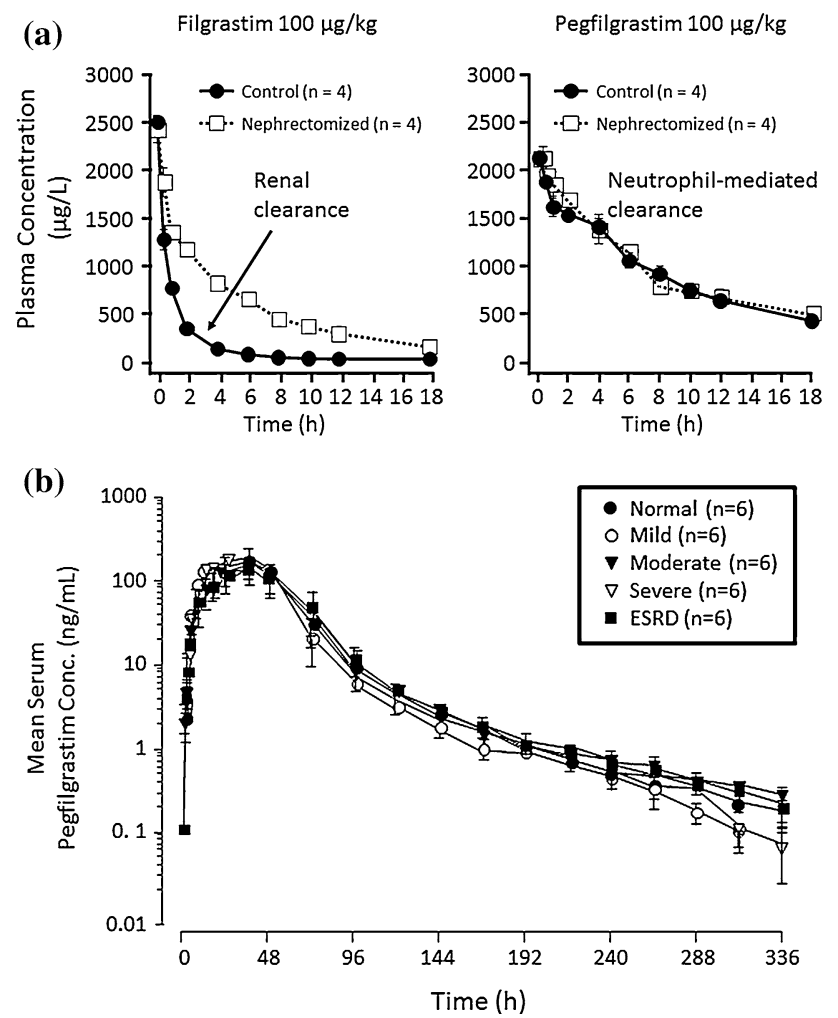

Fig. 4 The kidney plays an insignificant role in pegfilgrastim clearance. a Pharmacokinetic study in normal (sham-operated) and bilaterally nephrectomized mice (adapted from Yang et al. [48]). b Pharmacokinetic study in subjects with varying degrees of renal function. Subjects $(n=6)$ were given a single subcutaneous dose of pegfilgrastim $6 \mathrm{mg} / \mathrm{kg}$. Data are presented as mean \pm standard error of the mean (adapted from Yang et al. [49]). Conc. concentration, $E S R D$ end-stage renal disease similar (Fig. 4b), supporting the non-clinical observations that the kidney contribution to clearance is negligible.

Addition of the $20 \mathrm{kDa}$ PEG molecule increases both the molecular weight and the size of filgrastim. The molecular weight increases from $19 \mathrm{kDa}$ (filgrastim) to $39 \mathrm{kDa}$ (pegfilgrastim). This is still below the $60-70 \mathrm{kDa}$ molecular weight that is considered to be required to avoid glomerular filtration and subsequent renal elimination. The hydrodynamic radius, however, increases approximately 2.5- to 3-fold (calculated using equations in Fee and Van Alstine [50]). This increases the size of filgrastim from $\sim 4 \mathrm{~nm}$ to $\sim 6 \mathrm{~nm}$ in diameter. In general, proteins $\geq 6 \mathrm{~nm}$ in diameter (e.g., hemoglobin $6.4 \mathrm{~nm}$ and albumin $7 \mathrm{~nm}$ ) avoid glomerular filtration $[25,51]$. With the reduction in renal clearance, the primary means of pegfilgrastim removal from the circulation is by neutrophil-mediated clearance. Neutrophils and neutrophil precursors express G-CSF-R. This receptor binds pegfilgrastim and the drug-receptor complex is internalized and degraded inside the cell. Support for this hypothesis came from a comparison of pegfilgrastim clearance in wild-type versus G-CSF-R-deficient mice. In wild-type mice, serum concentrations of pegfilgrastim remained elevated for less than $48 \mathrm{~h}$ following injection of pegfilgrastim $10 \mu \mathrm{g} / \mathrm{kg}$; whereas serum concentrations of pegfilgrastim remained elevated for $144 \mathrm{~h}$ in G-CSF-R knockout mice [52].

Another consequence of the G-CSF-R/pegfilgrastim interaction is the stimulation of neutrophil precursor proliferation and differentiation. Figure 5 demonstrates the relationship between pegfilgrastim serum concentrations and circulating neutrophils in breast cancer patients treated with doxorubicin $\left(60 \mathrm{mg} / \mathrm{m}^{2}\right)$ and docetaxel $\left(75 \mathrm{mg} / \mathrm{m}^{2}\right)$, followed by a single injection of pegfilgrastim $(100 \mu \mathrm{g} / \mathrm{kg})$

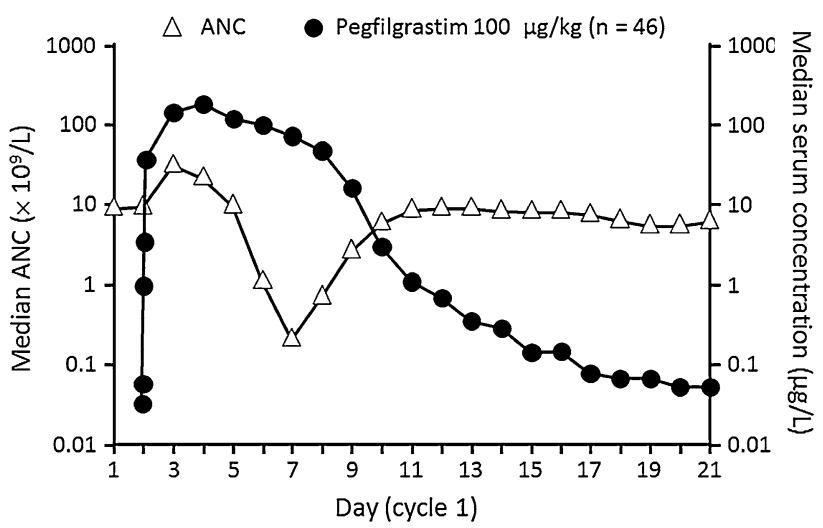

Fig. 5 Serum pegfilgrastim concentrations and absolute neutrophil count (ANC) profile in breast cancer patients treated with doxorubicin $\left(60 \mathrm{mg} / \mathrm{m}^{2}\right)$, docetaxel $\left(75 \mathrm{mg} / \mathrm{m}^{2}\right)$, and a single administration of pegfilgrastim $(100 \mu \mathrm{g} / \mathrm{kg})$. Reproduced from Holmes et al. [14] with permission of Wiley Materials (ㄷ 2008 American College of Clinical Pharmacology) 
1 day later [14]. After SC administration of pegfilgrastim, serum concentrations of pegfilgrastim were sustained during neutropenia. ANC levels started to increase after the nadir on day 7 , resulting in a rapid decline of serum concentrations of pegfilgrastim due to neutrophil-mediated clearance. Thus, during chemotherapy-induced neutropenia, circulating pegfilgrastim concentrations remain elevated until there is an increase in the ANC, which leads to increased pegfilgrastim consumption and self-regulated clearance. In comparison, serum concentrations of filgrastim were rapidly cleared after each injection, and multiple daily injections of filgrastim were required to maintain its clinical efficacy [14]. A semi-mechanistic model that includes neutrophil-mediated clearance adequately describes the relationship between pegfilgrastim serum concentrations and the ANC profile in healthy subjects [53] and in patients with non-small-cell lung cancer [54].

\subsection{Clinical Efficacy of Pegfilgrastim}

Pegfilgrastim is indicated to reduce the risk of FN in patients with non-myeloid malignancies receiving myelosuppressive chemotherapy. Approval of pegfilgrastim for use in patients with chemotherapy-induced neutropenia was based on results from two randomized, double-blind phase III studies in patients with breast cancer, designed to test the non-inferiority of pegfilgrastim versus filgrastim [46, 47]. Similar results were observed in both trials, demonstrating that a single fixed dose of pegfilgrastim per chemotherapy cycle was at least equivalent to daily doses of filgrastim in all efficacy endpoints including the duration of severe neutropenia (ANC $<0.5 \times 10^{9} / \mathrm{L}$ ), the depth of the ANC nadir in all cycles, the incidence of FN (neutropenia plus fever/infection), and rates of hospitalization and infection.

Subsequent clinical studies have shown pegfilgrastim to be similarly effective across a range of regimens and tumor types $[15,16,55,56]$. Meta-analyses of clinical studies have shown that pegfilgrastim reduces the risk of FN to a significantly greater extent than filgrastim $[57,58]$ and that pegfilgrastim also reduces the incidence of early mortality during chemotherapy [57, 59]. Observational studies, which include a broader range of patient populations than those eligible for clinical trials, indicate that pegfilgrastim is similarly effective in reducing FN risk in clinical practice $[60,61]$.

Unlike filgrastim, pegfilgrastim is not approved for stem cell mobilization, but clinical studies have shown that it is at least as effective as daily G-CSFs in mobilization of peripheral blood stem/progenitor cells and engraftment in the autologous and allogeneic setting [62-65].

\subsection{Clinical Safety of Pegfilgrastim}

Clinical safety data derived from the various clinical trials show that the safety profile of pegfilgrastim is comparable to that of filgrastim in terms of the total incidence of adverse events, incidence of adverse events attributed to study drug, and withdrawals due to adverse events. As with all G-CSFs, the most common adverse effect is bone pain, which is generally mild to moderate and manageable with non-narcotic analgesics. A patient-level analysis across multiple studies found that bone pain was experienced by more patients treated with pegfilgrastim than placebo, but that incidence of bone pain was similar between the pegfilgrastim- and filgrastim-treated groups [66]. Serious adverse reactions occur more rarely, and include splenic rupture, acute respiratory distress syndrome, allergic reactions, and potential for tumor growth stimulation effects on malignant cells [67]. As with all protein biologics, the potential for immunogenicity also exists, but neutralizing antibodies to pegfilgrastim have not been reported in clinical studies.

\section{Future Perspectives}

Pegfilgrastim was the only commercially available longacting G-CSF for more than 10 years, until the European approval of lipegfilgrastim in 2013 through the demonstration of clinical non-inferiority to pegfilgrastim in a randomized phase III study in patients with breast cancer [68]. Lipegfilgrastim is PEGylated on the O-linked glycosylation site at Thr-134; however, because this site is heterogeneously glycosylated when G-CSF is expressed in mammalian cells, the polysaccharide is added to the G-CSF protein core enzymatically using two recombinant glycosyltransferase enzymes and activated sugar nucleotide donor substrates in vitro. Subsequently, the PEG molecule is covalently attached to the polysaccharide [69].

Other PEGylated G-CSFs have been tested (Table 3), but few examples of approaches to extend the half-life of G-CSF exist outside of PEGylation. The most clinically advanced non-PEGylated molecules are benefilgrastim, which is a recombinant fusion protein of human $\mathrm{Fc}$ and G-CSF produced in mammalian cells [70] and balugrastim, which is a recombinant fusion protein of human serum albumin and G-CSF produced in yeast [71]. Benefilgrastim, which comprises two chains of human G-CSF-Fc, has recently been evaluated in a phase II study in patients with breast cancer [72]. In this study, benefilgrastim administered once per cycle at 240 or $320 \mu \mathrm{g} / \mathrm{kg}$ SC provided neutrophil support with a safety profile similar to that of pegfilgrastim during multiple chemotherapy cycles. 
Balugrastim has demonstrated non-inferiority to pegfilgrastim in a phase III study in patients with breast cancer, but it has not been approved for commercial use in either the USA or Europe. Since these molecules are administered in an identical manner to pegfilgrastim (injected once per chemotherapy cycle) and have not demonstrated superior clinical efficacy or safety, they may be better characterized as alternatives to pegfilgrastim rather than therapeutic advances.

Innovations in drug delivery provide additional possibilities for therapeutic improvements. Pegfilgrastim should be administered the day after chemotherapy [11] to avoid the risk of stimulating proliferation of myeloid progenitor cells in the presence of cytotoxic chemotherapy agents and worsening neutropenia outcomes [17]. Nonetheless, sameday administration of pegfilgrastim is observed in clinical practice [73], most likely due reasons of logistics or convenience. To overcome this problem, an on-body injector has been developed - a programmable delivery device attached to the patient's skin to deliver pegfilgrastim the day after chemotherapy - that eliminates the requirement for a patient to return to the clinic to receive pegfilgrastim [74]. This device, which was recently approved by the FDA (tradename OnPRO), may therefore increase patient compliance and increase the efficacy of pegfilgrastim in clinical practice.

Although not necessarily long-acting, small molecules capable of stimulating the G-CSF-R signaling pathway can provide the option of orally administered G-CSF, which may appeal to some patients. Several groups are pursuing this approach and have demonstrated in vitro and in vivo activity in preclinical studies [75-77], although currently they are in the early stages of clinical development. Clearly more work is needed in this area, including studies in human subjects and clinical testing against the available protein-based G-CSF products.

\section{Conclusion}

Filgrastim is a widely used short-acting G-CSF with a long-standing record of clinical efficacy and safety. To eliminate the need for daily injections and to maintain a similar safety profile, a long-acting form of filgrastim was designed that retained the core protein with additions to increase the molecular size and extend the circulating halflife. PEGylation was considered useful for therapeutic proteins: it is non-toxic; it can improve properties related to immunogenicity, stability, and aggregation; and it can enhance the pharmacokinetic/pharmacodynamic profiles as a conjugation partner. In addition, technology has been developed so that it can be added to specific sites on the protein to limit the potential for interference with receptor binding, and it is possible generate PEG moieties with a range of sizes to enable selection of a modified protein with optimal pharmacokinetic/pharmacodynamic profiles. Pegfilgrastim contains a single linear $20 \mathrm{kDa}$ PEG attached to the N-terminal amino acid of filgrastim, and the pharmacokinetic profile has been sufficiently improved by significantly reducing the renal clearance. As such, a single dose of pegfilgrastim effectively reduces the risk of neutropenia and neutropenia-associated complications for an entire chemotherapy cycle.

Acknowledgments Tara Arvedson, James O'Kelly, and Bing-Bing Yang are employees of and own stocks in Amgen Inc., the manufacturer of filgrastim and pegfilgrastim.

Author contributions Tara Arvedson conceived the idea for the manuscript, wrote the first draft, and is the guarantor for the overall content. James O'Kelly and Bing-Bing Yang wrote and edited subsequent drafts of the manuscript.

Open Access This article is distributed under the terms of the Creative Commons Attribution-NonCommercial 4.0 International License (http://creativecommons.org/licenses/by-nc/4.0/), which permits any noncommercial use, distribution, and reproduction in any medium, provided you give appropriate credit to the original author(s) and the source, provide a link to the Creative Commons license, and indicate if changes were made.

\section{References}

1. Welte K, Gabrilove J, Bronchud $\mathrm{MH}$, et al. Filgrastim (rmetHuG-CSF): the first 10 years. Blood. 1996;88(6):1907-29.

2. Donadieu J, Leblanc T, Bader Meunier B, et al. French Severe Chronic Neutropenia Study Group. Analysis of risk factors for myelodysplasias, leukemias and death from infection among patients with congenital neutropenia. Experience of the French Severe Chronic Neutropenia Study Group. Haematologica. 2005;90(1):45-53.

3. Dancey J, Deubelbeiss KA, Harker LA, et al. Neutrophil kinetics in man. J Clin Invest. 1976;58(3):705-15.

4. Pillay J, den Braber I, Vrisekoop N, et al. In vivo labeling with $2 \mathrm{H} 2 \mathrm{O}$ reveals a human neutrophil lifespan of 5.4 days. Blood. 2010;116(4):625-7.

5. Ogawa M. Differentiation and proliferation of hematopoietic stem cells. Blood. 1993;81:2844-53.

6. Arvedson T, Molineux G. Use of r-metHuG-CSF to enable chemotherapy delivery for solid tumors, in twenty years of G-CSF. In: Molineux G, Foote M, Arvedson T, editors. Twenty Years of G-CSF. Clinical and nonclincal discoveries. Springer; 2012. p. 151-68.

7. Bonadonna G, Valagussa P, Moliterni A, et al. Adjuvant cyclophosphamide, methotrexate, and fluorouracil in node-positive breast cancer - the results of 20 years of follow-up. N Engl J Med. 1995;332(14):901-6.

8. Chirivella I, Bermejo B, Insa A, et al. Optimal delivery of anthracycline-based chemotherapy in the adjuvant setting improves outcome of breast cancer patients. Breast Cancer Res Treat. 2009;114(3):479-84.

9. Agboola O, Crawford J, Dale D, et al. Most patients treated with adjuvant chemotherapy for breast cancer receive substantially 
reduced dose intensity [abstract no. 110]. American Society of Clinical Oncologists (ASCO), 31 May-3 Jun 2003, Chicago.

10. Kuwabara T, Kobayashi S, Sugiyama Y. Pharmacokinetics and pharmacodynamics of a recombinant human granulocyte colonystimulating factor. Drug Metab Rev. 1996;28(4):625-58.

11. Amgen. Neupogen ${ }^{\circledR}$ (filgrastim): US prescribing information. Thousand Oaks: Amgen Inc.; 2007.

12. Green MD, Koelbl H, Baselga J, et al. A randomized doubleblind multicenter phase III study of fixed-dose single-administration pegfilgrastim versus daily filgrastim in patients receiving myelosuppressive chemotherapy. Ann Oncol. 2003;14(1):29-35.

13. Molineux G. Pegfilgrastim - designing an improved form of rmetHu-GCSF. In: Veronese FM, editor. Pegylated protein drugs: basic science and clinical applications. Basel: Birkhauser; 2009. p. $169-85$.

14. Holmes FA, Jones SE, O'Shaughnessy J, et al. Comparable efficacy and safety profiles of once-per-cycle pegfilgrastim and daily injection filgrastim in chemotherapy-induced neutropenia: a multicenter dose-finding study in women with breast cancer. Ann Oncol. 2002;13(6):903-9.

15. Balducci L, Al-Halawani $\mathrm{H}$, Charu V, et al. Elderly cancer patients receiving chemotherapy benefit from first-cycle pegfilgrastim. Oncologist. 2007;12(12):1416-24.

16. Hecht JR, Pillai M, Gollard R, et al. A randomized, placebocontrolled phase ii study evaluating the reduction of neutropenia and febrile neutropenia in patients with colorectal cancer receiving pegfilgrastim with every-2-week chemotherapy. Clin Colorectal Cancer. 2010;9(2):95-101.

17. Burris HA, Belani CP, Kaufman PA, et al. Pegfilgrastim on the same day versus next day of chemotherapy in patients with breast cancer, non-small-cell lung cancer, ovarian cancer, and nonhodgkin's lymphoma: results of four multicenter, double-blind, randomized phase II studies. J Oncol Pract. 2010;6(3):133-40.

18. Vogel CL, Wojtukiewicz MZ, Carroll RR, et al. First and subsequent cycle use of pegfilgrastim prevents febrile neutropenia in patients with breast cancer: a multicenter, double-blind, placebocontrolled phase III study. J Clin Oncol. 2005;23(6):1178-84

19. Molineux G. The design and development of pegfilgrastim (PEGrmetHuG-CSF, Neulasta $^{\circledR}$ ). Curr Pharm Des. 2004;10:1235-44.

20. Renwick W, Pettengell R, Green M. Use of filgrastim and pegfilgrastim to support delivery of chemotherapy. BioDrugs. 2009;23(3):175-86.

21. Crawford J, Ozer H, Stoller R, et al. Reduction by granulocyte colony-stimulating factor of fever and neutropenia induced by chemotherapy in patients with small-cell lung cancer. N Engl J Med. 1991;325(3):164-70.

22. Trillet-Lenoir V, Green J, Manegold C, et al. Recombinant granulocyte colony stimulating factor reduces the infectious complications of cytotoxic chemotherapy. Eur J Cancer. 1993;29(3):319-24.

23. Raso SW, Abel J, Barnes JM, et al. Aggregation of granulocytecolony stimulating factor in vitro involves a conformationally altered monomeric state. Protein Sci. 2005;14(9):2246-57.

24. Ohlson M, Sörensson J, Lindström K, et al. Effects of filtration rate on the glomerular barrier and clearance of four differently shaped molecules. Am J Physiol Renal Physiol. 2001;281(1):F103-13.

25. Sarin H. Physiologic upper limits of pore size of different blood capillary types and another perspective on the dual pore theory of microvascular permeability. J Angiogenes Res. 2010;2:14.

26. Harris JM, Chess RB. Effect of pegylation on pharmaceuticals. Nat Rev Drug Discov. 2003;2(3):214-21.

27. Sherman MR, et al. Conjugation of high-molecular weight poly(ethylene glycol) to cytokines: granulocyte-macrophage colony-stimulating factors as model substrates. In: Harris JM,
Zalipsky S, editors. Poly(ethylene glycol). American Chemical Society, San Francisco, CA, 1997. p. 155-69.

28. Kusterle M, Jevsevar S, Porekar VG. Size of pegylated protein conjugates studied by various methods. Acta Chim Slov. 2008;55:594-601.

29. Clark R, Olson K, Fuh G, et al. Long-acting growth hormones produced by conjugation with polyethylene glycol. J Biol Chem. 1996;271(36):21969-77.

30. Kontermann R. Half-life modulating strategies - an introduction. In: Kontermann R, editor. Therapeutic proteins: strategies to modulate their plasma half-lives. Weinheim: Wiley-Blackwell; 2012. p. 3-21.

31. Fruijtier-Polloth C. Safety assessment on polyethylene glycosols (PEGs) and their derivaties as used in cosmetic products. Toxicology. 2005;214:1-38.

32. Working PK, Newman MS, Johnson J, et al. Safety of poly(ethylene glycol) and poly(ethylene glycol) derivatives. In: Harris JM, Zalipsky S, editors. Poly(ethylene glycol): chemistry and biological applications. Washington, DC: ACS Books; 1997. p. 45-54.

33. Zeidan A, Wang ES, Wetzler M. Pegasparaginase: where do we stand? Expert Opin Biol Ther. 2009;9(1):111-9.

34. Fishburn CS. The pharmacology of PEGylation: balancing PD with PK to generate novel therapeutics. J Pharm Sci. 2008;97(10): 4167-83.

35. Piedmonte DM, Treuheit MJ. Formulation of Neulasta ${ }^{\circledR}$ (pegfilgrastim). Adv Drug Deliv Rev. 2008;60(1):50-8.

36. Zalipsky S. Chemistry of polyethylene glycol conjugates with biologically active molecules. Adv Drug Deliv Rev. 1995;16(2-3):157-82.

37. Arakawa T, Prestrelski SJ, Narhi LO, et al. Cysteine 17 of recombinant human granulocyte-colony stimulating factor is partially solvent-exposed. J Protein Chem. 1993;12(5):525-31.

38. Zhao H, Greenberger L, Horak I. Drug conjugates with poly(ethylene glycol). In: Kratz F, Senter P, Steinhagen H, editors. Drug delivery in oncology: from basic research to cancer therapy. Weinheim: Wiley; 2013. p. 627-66.

39. Davis F. PEG-adenosine deaminase and PEG-asparaginase, In: Maeda H, Kabanov A, Kataoka K, et al., editors. Polymer drugs in the clinical stage: advances in experimental medicine and biology. New York: Springer USA; 2003. p. 51-8.

40. Satake-Ishikawa R, Ishikawa M, Okada Y, et al. Chemical modification of recombinant human granulocyte colony-stimulating factor by polyethylene glycol increases its biological activity in vivo. Cell Struct Funct. 1992;17(3):157-60.

41. Yamasaki M, Asano M, Okabe M, et al. Modification of recombinant human granulocyte colony-stimulating factor (rhGCSF) and its derivative ND 28 with polyethylene glycol. J Biochem. 1994;115:814-9.

42. Tamada T, Honjo E, Maeda Y, et al. Homodimeric cross-over structure of the human granulocyte colony-stimulating factor (GCSF) receptor signaling complex. Proc Natl Acad Sci USA. 2006;103(9):3135-40.

43. Wong S. Reactive groups of proteins and their modifying agents. In: Chemistry of protein conjugations and cross-linking. Boca Raton: CRC Press, Inc.; 1991. p. 7-45.

44. Bowen $\mathrm{S}$, Tare N, Inoue $\mathrm{T}$, et al. Relationship between molecular mass and duration of activity of polyethylene glycol conjugated granulocyte colony-stimulating factor mutein. Exp Hematol. 1999;27(3):425-32.

45. Roseng L, Tolleshaug H, Berg T. Uptake, intracellular transport, and degradation of polyethylene glycol-modified asialofetuin in hepatocytes. J Biol Chem. 1992;267(32):22987-93.

46. Yang B-B, Kido A. Pharmacokinetics and pharmacodynamics of pegfilgrastim. Clin Pharmacokinet. 2011;50(5):295-306. 
47. Yang BB, Savin MA, Green M. Prevention of chemotherapyinduced neutropenia with pegfilgrastim: pharmacokinetics and patient outcomes. Chemotherapy. 2012;58(5):387-98.

48. Yang B-B, Lum PK, Hayashi MM, et al. Polyethylene glycol modification of filgrastim results in decreased renal clearance of the protein in rats. J Pharm Sci. 2004;93(5):1367-73.

49. Yang B-B, Kido A, Salfi M, et al. Pharmacokinetics and pharmacodynamics of pegfilgrastim in subjects with various degrees of renal function. J Clin Pharmacol. 2008;48(9):1025-31.

50. Fee CJ, Van Alstine JM. Prediction of the viscosity radius and the size exclusion chromatography behavior of PEGylated proteins. Bioconjug Chem. 2004;15:1304-13.

51. Fujigaki Y, Nagase M, Kobayasi S, et al. Intra-GBM site of the functional filtration barrier for endogenous proteins in rats. Kidney Int. 1993;43(3):567-74.

52. Kotto-Kome AC, Fox SE, Lu W, et al. Evidence that the granulocyte colony-stimulating factor (G-CSF) receptor plays a role in the pharmacokinetics of G-CSF and PegG-CSF using a G-CSF-R KO model. Pharmacol Res. 2004;50(1):55-8.

53. Roskos LK, Lum P, Lockbaum P, et al. Pharmacokinetic/pharmacodynamic modeling of pegfilgrastim in healthy subjects. J Clin Pharmacol. 2006;46(7):747-57.

54. Yang BB. Integration of pharmacokinetics and pharmacodynamics into the drug development of pegfilgrastim, a pegylated protein. In: Meibohm B, editor. Pharmacokinetics and pharmacodynamics of biotech drugs: principles and case studies in drug development. Weinheim: Wiley-Blackwell; 2006. p. 373-93.

55. Grigg A, Solal-Celigny P, Hoskin P, et al. Open-label, randomized study of pegfilgrastim vs. daily filgrastim as an adjunct to chemotherapy in elderly patients with non-Hodgkin's lymphoma. Leuk Lymphoma. 2003;44:1503-8.

56. Pinter T, Abella, S, Cesas A et al. Results of a phase III, randomized, double-blind, placebo-controlled trial of pegfilgrastim (PEG) in patients (pts) receiving first-line FOLFOX or FOLFIRI and bevacizumab (B) for colorectal cancer (CRC) [abstract no. 3575]. J Clin Oncol. 2013. 31(Suppl 4):LBA445.

57. Kuderer NM, Dale DC, Crawford J, et al. Impact of primary prophylaxis with granulocyte colony-stimulating factor on febrile neutropenia and mortality in adult cancer patients receiving chemotherapy: a systematic review. J Clin Oncol. 2007;25(21): 3158-67.

58. Cooper KL, Madan J, Whyte S, et al. Granulocyte colony-stimulating factors for febrile neutropenia prophylaxis following chemotherapy: systematic review and meta-analysis. BMC Cancer. 2011;11:404.

59. Lyman H, Kuderer NM, Crawford, J et al. Impact of pegfilgrastim on early all-cause mortality in patients receiving cancer chemotherapy [abstract]. J Clin Oncol. 2008;26(Suppl):6552.

60. Almenar C, Bosch Roig C, Jiménez Orozco E, et al. LEARN II Study Group. Effectiveness of daily versus non-daily granulocyte colony-stimulating factors in patients with solid tumours undergoing chemotherapy: a multivariate analysis of data from current practice. Eur J Cancer Care (Engl). 2013;22(3):400-12.

61. Hershman D, Hurley D, Wong M, et al. Impact of primary prophylaxis on febrile neutropenia within community practices in the US. J Med Econ. 2009;12(3):203-10.

62. Ocheni S, Zabelina T, Bacher U, et al. Pegfilgrastim compared to lenograstim after allogeneic peripheral blood stem-cell transplantation from unrelated donors. Leuk Lymphoma. 2009;50(4):612-8.

63. Cesaro S, Nesi F, Tridello G, et al. A randomized, non-inferiority study comparing efficacy and safety of a single dose of pegfilgrastim versus daily filgrastim in pediatric patients after autologous peripheral blood stem cell transplant. PLoS One. 2013;8(1):e53252.

64. Gerds A, Fox-Geiman M, Dawravoo K, et al. Randomized phase III trial of pegfilgrastim versus filgrastim after autologus peripheral blood stem cell transplantation. Biol Blood Marrow Transplant. 2010;16(5):678-85.

65. Willis F, Woll P, Theti D, et al. Pegfilgrastim for peripheral CD34+ mobilization in patients with solid tumours. Bone Marrow Transplant. 2009;43(12):927-34.

66. Gregory SA, Schwartzberg LS, Mo M et al. Evaluation of reported bone pain in cancer patients receiving chemotherapy in pegfilgrastim clinical trials: a retrospective analysis. Community Oncology. 2010;7(7):297-308.

67. Amgen. Neulasta (pegfilgrastim): full prescribing information. Thousand Oaks: Amgen Inc.; 2014.

68. Bondarenko I, Gladkov OA, Elsaesser R, et al. Efficacy and safety of lipegfilgrastim versus pegfilgrastim: a randomized, multicenter, active-control phase 3 trial in patients with breast cancer receiving doxorubicin/docetaxel chemotherapy. BMC Cancer. 2013;13:386.

69. European Medicines Agency. Lonquex: EPAR product information: summary of product characteristics. London: European Medicines Agency; 2013.

70. Cox GN, Chlipala EA, Smith DJ, et al. Hematopoietic properties of granulocyte colony-stimulating factor/immunoglobulin (G$\mathrm{CSF} / \mathrm{IgG}-\mathrm{Fc}$ ) fusion proteins in normal and neutropenic rodents. PLoS One. 2014;9(3):e91990.

71. Avisar N, Adar L, Bock J, et al. First-in-human, phase I/IIa doseescalation and safety study of balugrastim in breast cancer patients receiving myelosuppressive chemotherapy. Cancer Chemother Pharmacol. 2015;75(5):929-39.

72. Glaspy J, Tang T, Rutty D, et al. A phase II, randomized, multicentre, open-label, active-controlled, dose-finding trial of F-627 (benefilgrastim) in women with breast cancer receiving myelotoxic chemotherapy [abstract no. 1584]. In: 56th annual meeting of the American Society of Hematology; 6-9 Dec 2014; San Francisco.

73. Weycker D, Wu H, Hagiwara M, et al. Use of chemotherapy and same-day pegfilgrastim prophylaxis in US clinical practice [abstract no. 4825]. In: 56th annual meeting of the American Society of Hematology; 6-9 Dec 2014; San Francisco.

74. Yang BB, Morrow PK, Wu X, Moxness M, Padhi D et al. Comparison of pharmacokinetics and safety of pegfilgrastim administered by two delivery methods: on-body injector and manual injection with a prefilled syringe. Cancer Chemother Pharmacol. 2015;1-8. doi:10.1007/s00280-015-2731-x.

75. Marschke K, Vajda E, Zhi L. Novel small-molecule human G-CSF receptor agonist stimulates neutrophil counts in monkeys and displays anti-proliferative effects on tumor cells mediated by a reduction of intracellular iron [abstract no. 3462]. In: 55th annual meeting of the American Society of Hematology;7-10 Dec 2013; New Orleans.

76. Kusano K, Ebara S, Tachibana K, et al. A potential therapeutic role for small nonpeptidyl compounds that mimic human granulocyte colony-stimulating factor. Blood. 2004;103:836-42.

77. Tian S-S, Lamb P, King AG, et al. A small, nonpeptidyl mimic of granulocyte-colony-stimulating factor. Science. 1998;281(5374): 257-9.

78. Molineux G, Kinstler O, Briddell B, et al. A new form of Filgrastim with sustained duration in vivo and enhanced ability to mobilize PBPC in both mice and humans. Exp Hematol. 1999;27(12):1724-34.

79. Viens P, Maraninchi D. High-dose chemotherapy in advanced breast cancer. Crit Rev Oncol Hematol. 2002;41(2):141-9.

80. Salafet O, Ruzina ND, Ponomarenko NA, et al. Diagnostic and pathogenetic implications of the site specificity of antibody proteases in multiple sclerosis [in Russian]. Vestn Ross Akad Med Nauk. 2010;4:8-15.

81. Scholz M, Engel C, Apt D, et al. Pharmacokinetic and pharmacodynamic modelling of the novel human granulocyte colony- 
stimulating factor derivative Maxy-G34 and pegfilgrastim in rats. Cell Prolif. 2009;42(6):823-37.

82. Schwartzberg L, Sankar SL, Apt D, et al. An open-label, doseescalating study of Maxy-G34, a novel potent, long-acting pegylated G-CSF, compared with pegfilgrastim (PF) for the treatment of chemotherapy induced neutropenia (CIN) [abstract no. e14500]. American Society of Clinical Oncology annual meeting; 29 May-2 Jun 2009; Orlando.

83. Tanaka H, Kaneko T. Pharmacokinetic and pharmacodynamic comparisons between human granulocyte colony-stimulating factor purified from human bladder carcinoma cell line 5637 culture medium and recombinant human granulocyte colony-stimulating factor produced in Escherichia coli. J Pharmacol Exp Ther. 1992;262(1):439-44.

84. Scaramuzza S, Tonon G, Olianas A, et al. A new site-specific monoPEGylated filgrastim derivative prepared by enzymatic conjugation: production and physicochemical characterization. J Control Release. 2012;164(3):355-63. 